\title{
Geo-Spatial Modelling of Habitat Suitability of wildlife species of Kuno Wildlife Sanctuary
}

\author{
Kush Kushwah $^{1}$, R.J. Rao ${ }^{2}$, Bidyalakshmi Phurailatpam ${ }^{3}$ \\ ${ }^{1,2(}$ IGAEERE, School of Studies in Environmental Science) \\ ${ }^{3}$ Conservation Biology Unit, School of studies in Zoology )(Jiwaji University, Gwalior, Madhya Pradesh, \\ India)
}

\begin{abstract}
Predicting species habitat in a wildlife sanctuary is essential in management and conservation process of the species. Habitat map appear most capable of providing information on the distribution of large numbers of species in a wider variety of habitat types. Integrated GIS and Remote Sensing have already successfully been applied to map the distribution of several plant and animal species, their ecosystems, landscapes, bio-climatic conditions and factors facilitating invasions. The present study is carried out using the technologies of Remote Sensing and GIS to predict and model the habitat suitability of some herbivorous species of Kuno Wildlife Sanctuary for better management and conservation in a cost-effective way. The paper presents the habitat suitability of the various wildlife species found in the sanctuary. The sanctuary was categorized into 9 habitats - Mixed forest, Dense Forest, Open Forest, Kardhai forest, Khair- Kardhai forest, Dhawa forest, Khair forest, Dry/ Barren land and Water bodies using supervised classification. Wildlife species were surveyed using point count and distance sampling techniques while registering the coordinates with a GPS from 2008 to 2010. Geo-statistical Kriging and Co-Kriging methods were used to calculate the predictable habitat of the wild prey species encountered taking into account the proximity to water availability, habitat type, slope, aspect, distance from human habitats, etc.
\end{abstract}

Keywords- Remote Sensing, GIS, Geo-statistical Kriging, Wildlife Species, Habitat Suitability Map

\section{INTRODUCTION}

Understanding species distributions across space and time is essential in ecology, evolution and in conservation of species diversity ([1]). Models of species distributions are often used in the examination of conservation issues, such as to evaluate potential management actions and interpret the effects of climate change and are frequently used in spatial conservation planning ([2], [3], [4]). Besides, knowledge of habitat preferences and their requirements are very important in habitat mapping of species of interest. Integrated GIS and Remote Sensing have already successfully been applied to map the distribution of several plant and animal species, their ecosystems, landscapes, bio-climatic conditions and factors facilitating invasions ([5] and [6], [7], [8], [9]). A multitude of remote sensing-based habitat mapping and monitoring approaches have been developed, ranging from photo-interpretation by humans to automated quantitative algorithms by computers, often with several methods in combination ([10], [11]). [12] predicted species richness and occurrences of terrestrial mammals from Principal Component Analysis (PCA) ordinate land cover variables from the Land Cover Map of Great Britain. [13] directly correlated the distribution of large mammalian herbivores in the Okavango delta in Botswana with Landsat Thematic Mapper (TM) and Enhanced Thematic Mapper (ETM+) reflectance data. [14] used Landsat and ETM+ imagery for mapping of land cover change in a reindeer herding area of the Russian Arctic. [15] used satellite imagery and GIS to evaluate wildlife habitat suitability mapping, mainly for Asian elephants in Thailand. Many other researchers have also successfully predicted habitat suitability of wildlife species using Remote Sensing and GIS technologies. Habitat map appear most capable of providing information on the distribution of large numbers of species in a wider variety of habitat types. This is strongly limited by variation in species composition, and best applied over limited spatial extents of tens of square kilometers ([16]).

The present study is carried out in Kuno Wildlife Sanctuary which have an area of about $344.686 \mathrm{sq}$ $\mathrm{km}$ and located between latitudes of $2530^{\prime} \mathrm{N}$ to $25^{\circ} 53^{\prime} \mathrm{N}$ and longitudes of $77^{\circ} 07^{\prime} \mathrm{E}$ to $77^{\circ} 28^{\prime} \mathrm{E}$ in Sheopur district in Madhya Pradesh in India. A perennial river Kuno bisects the sanctuary in the middle. The forest in Kuno Wildlife Sanctuary falls under the Northern Tropical Dry Deciduous Forest and is dominated by Khair (Acacia catechu), Kardhai (Anogeissus pendula), Dhow (Anogeissus latifolia), Salai (Boswellia serrata) and Gunja (Lannea coromandelica) ([17]). These species are found in various combinations depending on the slope and other governing factors ([18]). The sanctuary also supports large varieties of both herbivorous and carnivorous wildlife species. Chital, Chinkara, Sambar, Blackbuck, Nilgai, Wild Pig and Languar, etc are some of the herbivorous or prey species reported in the sanctuary. The carnivorous species reported includes Jackal, Bear, Leopard, Wolf, Wild Cat, Tiger, etc. The survival and distribution of wildlife species is highly dependent 
on its habitat and any management practice that maintains or improve the diversity and availability of food in a habitat will increase the potential population size of wildlife species ([19]). Predicting the distribution of wildlife species from habitat data is frequently perceived to be a useful technique and should be done in very cost-efficient manners. Traditional methods are time consuming and expensive and therefore the present study is carried out using the techniques of Remote Sensing and GIS to predict and model the habitat suitability of some herbivorous species of the sanctuary for better management and conservation in a cost-effective way.

\section{METHODS}

Multi-temporal satellite imageries such as Landsat data of sensors TM of $05^{\text {th }}$ October 1990 and LISS III IRS-P6 of $02^{\text {nd }}$ March 2008 were used in the study. The imageries were geo-corrected and Digital Image Processing such as supervised classification was applied with limited ground truthing to characterize the habitat type of the sanctuary. Accuracy assessment was performed for each habitat type generated. Animal distribution was sampled along 24 beat wise within the sanctuary laid by the M.P. Forest Department while registering the locations with a Global Positioning System (GPS), and the recorded animal presence was related to the spectral signature of the location. Point count survey method and distance sampling method was used to estimate the relative abundance of wild prey species, etc. ([20], [21], [22]). In order to adequately sample these areas, vehicle transects were used. Each transect varied in length from 4 to 10 kilometers and measures were taken to ensure that transects were randomly distributed over the entire area, encompassing differing vegetation and terrain types for the study site. And for each animal sighted during the survey, their coordinates were recorded by Garmin GPS 60 and simultaneously their habitat features of the location were noted for data analysis and interpretation.

The GPS points collected for presence data of animals were converted to UTM WGS 84 Zone $43 \mathrm{~N}$ projection similar to that of the satellite image and were superimposed on the satellite image portraying the encounter rate of the wildlife species. Then the encounter map of each species was overlay with the habitat type and other environmental factor maps and preferable habitat map were generated. Geo-statistical analyses was used to analyze spatial variability of prey species at different observation points since each prey that is measured is associated with its observation location $x$. Kriging and Co-Kriging methods were used to generate the predictable habitat of the wild prey species encountered taking into account the proximity to water availability, habitat type, slope, aspect, distance from human habitats, etc. The overall concept of the methods was given in Fig. 1.

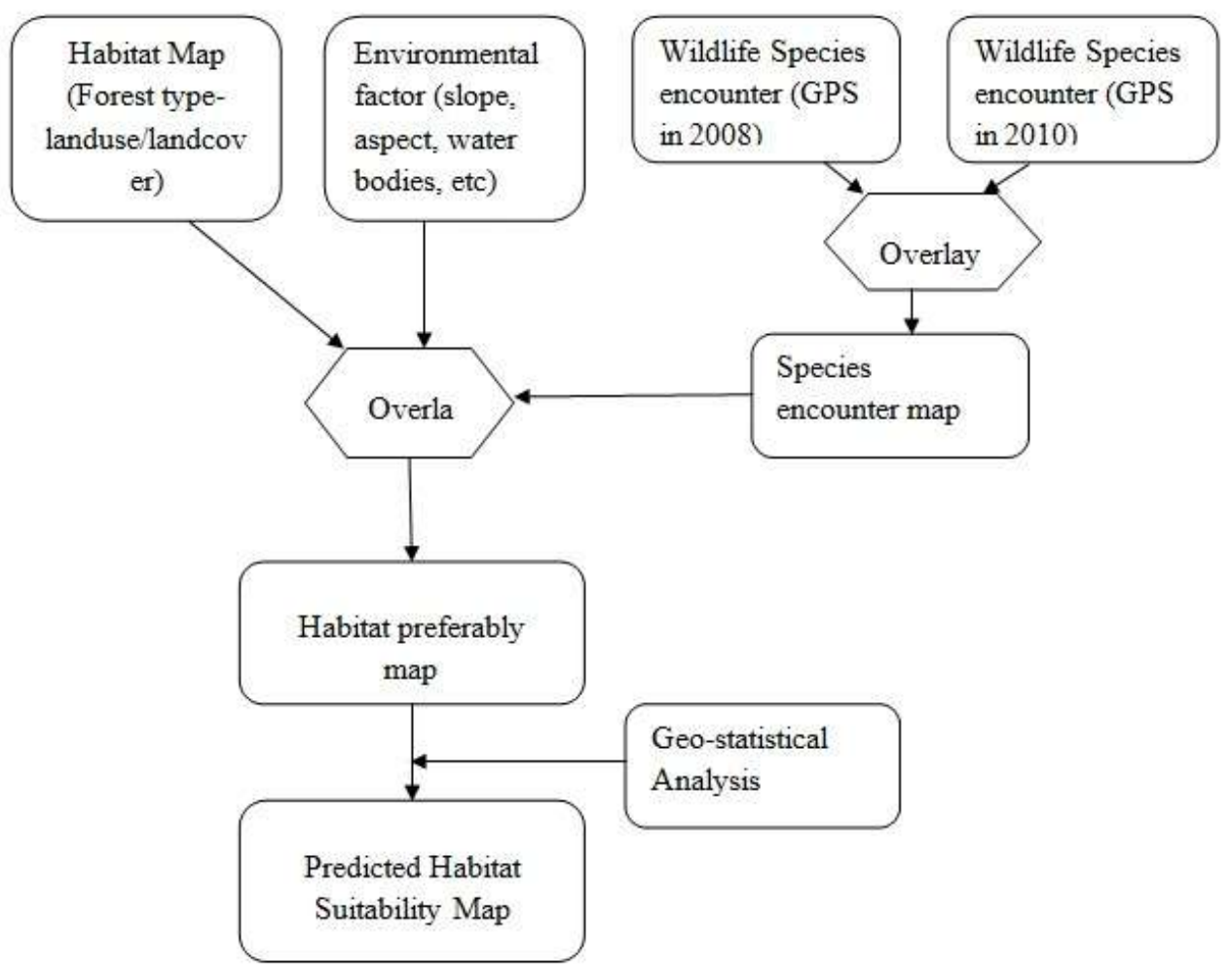

Fig. 1. Conceptual flowchart for Habitat Suitability Mapping 


\subsection{Habitat type}

\section{RESULT}

In this study, the habitat type of Kuno Wildlife Sanctuary, KWS was classified into 9 classes as Mixed forest, Dense Forest, Open Forest, Kardhai forest, Khair- Kardhai forest, Dhawa forest, Khair forest, Dry/ Barren land and Water bodies. Mixed forest is the dominant vegetation type in the area followed by dense forest and Kardai forest. About $23.36 \%$ of forest sanctuary is dominated by mixed forest which is a combination of tree species like Kardai, Khair, Palash, tendu, salai and short grasses. Dense forest comprising of tree species salai, kardai, dhawa, khair, harron, dudhi covered about $16.9 \%$ of the sanctuary followed by Kardhai forest (12.93\%), Dhawa (12.8\%), Khair forest(11.8\%). Open Mixed forest comprising of high density grassland and agricultural plots converted to sparse trees of khair occupied about $11.07 \%$ of the sanctuary while KhairKardhai forest which is dominated by Khair tree species by $7.32 \%$ ). Water bodies occupies approximately around $0.85 \%$ in this classification but varies according to the season-wise and also of Dry/Barren areas (2.9\%) comprising of stones, dry land, etc (Table 1).

Table 1. Area of different habitat type in KWS

\begin{tabular}{|l|l|r|}
\hline Forest Type & Area in ha & Area (\%) \\
\hline Khair_Khardai_Forest & 2626 & 7.32 \\
\hline Dense_forest & 6052 & 16.89 \\
\hline Mixed_forest & 8375 & 23.36 \\
\hline Dhawa & 4607 & 12.85 \\
\hline Khair_forest & 4220 & 11.8 \\
\hline Kardhai_forest & 4637 & 12.93 \\
\hline Open_mixed_forest & 3969 & 11.07 \\
\hline Dry_area & 1051 & 2.9 \\
\hline Water & 306.7 & 0.85 \\
\hline
\end{tabular}

\subsection{Preferable habitat of Herbivorous species}

The analysis indicates that chital was the most widely distributed species found throughout the sanctuary with an encounter rate of 1.224/ha and 0.244/ha in 2010 and 2008 (Fig. 2). As estimated, chital has a group mean density of $17.1 \pm 12.8 \mathrm{SD}$ in 2010 which shows that this species is the most abundant among all the prey species in the sanctuary. They are mostly encountered at the habitat of high grassland and also at open mixed vegetation not far from water sources. Chital usually drinks water once a day and more frequently in summer which restricts them to forest tracts with assured presence of water (IUCN, 2008). It was observed that chital are mostly found at a moderate slope of $5^{\circ}-13^{\circ}$ and avoid steep to steepest slope. They are often observed in a group of 5 to 7 but sometimes also found in huge numbers in a particular habitat.

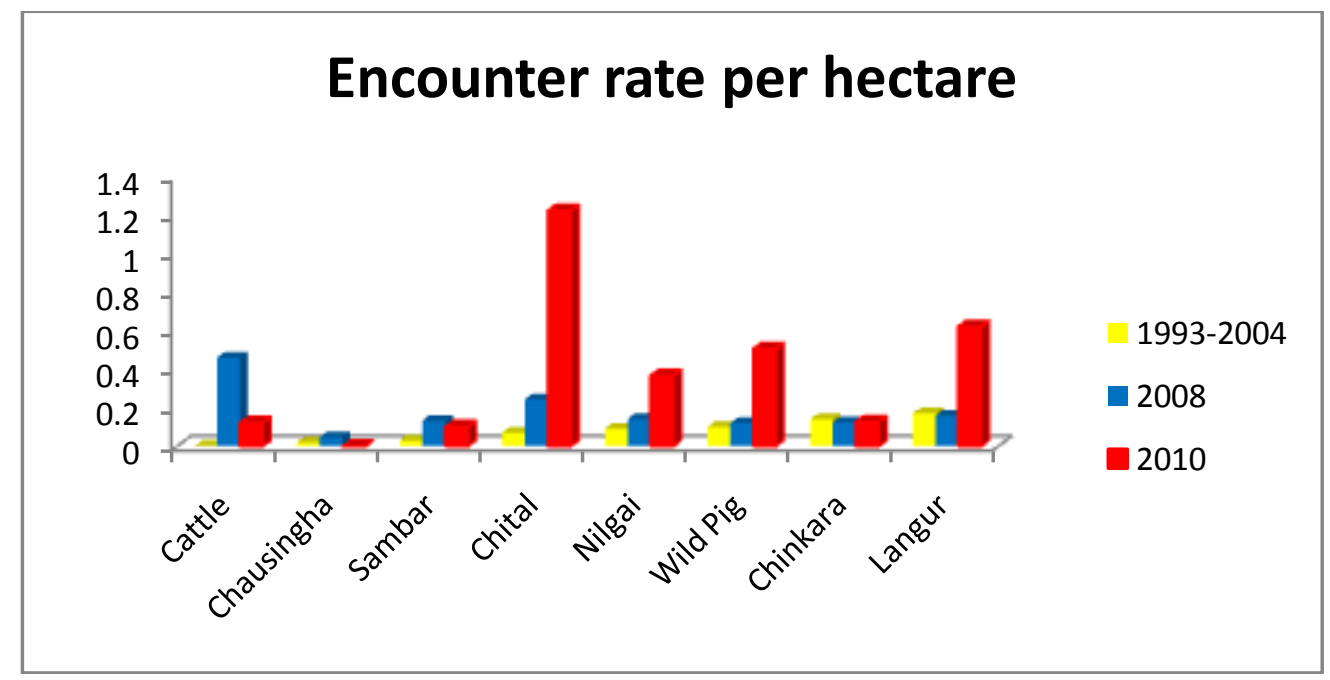

Fig. 2. Encounter rate of wild herbivorous in 1993/2004, 2008 and 2010. (Source: Year 19932004; M.P. Forest Department)

The next abundant species observed was Langur and wild pig with an encounter rate of $0.62269 / \mathrm{ha}$ and $0.505994 /$ ha in 2010 and $0.159 /$ ha and $0.119 /$ ha in 2008 . Langur has a group mean density of $16.8 \pm 22.9$ SD while wild pig has $10.8 \pm 12.1 \mathrm{SD}$. Since these two species does not come into important wild prey categories and 
their habitat were not analyzed though there encounter rate was noted. Nilgai, with an encounter rate of 0.367/ha in 2010 and $0.142 /$ ha in 2008 was the next abundant prey species after chital which was also observed to be distributed throughout the sanctuary though they preferred more open and flat areas with high grass diversity and trees lopping (IUCN 2008). Their group mean density was estimated to be $8.5 \pm 5.2 \mathrm{SD}$. Chinkara is also another prey species with an encounter rate of $0.125 /$ ha in 2010 and $0.123 /$ ha in 2008 . They are mostly observed at open forest with high density of grasses and also in mixed forest. They have a group mean density of $6.7 \pm 6.1$ SD. Sambar, on the other hand with an encounter rate of 0.132/ha in 2008 and $0.101 /$ ha in 2010 are observed more at high altitude with high canopy trees and herb density. The estimated group means density of this species is about 5.1 \pm 4.6 SD. They are mostly encounter at a steep slope of $15^{\circ}-25^{\circ}$ and avoid open forest area. Their pugmark indicates that they also wander frequently around water bodies with salt licks.

\subsection{Cluster Analysis}

The Hierarchical cluster analysis was done according to the presence/absence of herbivorous species found in KWS during the survey period. The analysis show clustering of vegetation types Harron, Khair, Salai and Palash. Two more clustering were found in between Ber-Reonja and Dhawa-Baheda.

\section{Rescaled Distance Cluster Combine}

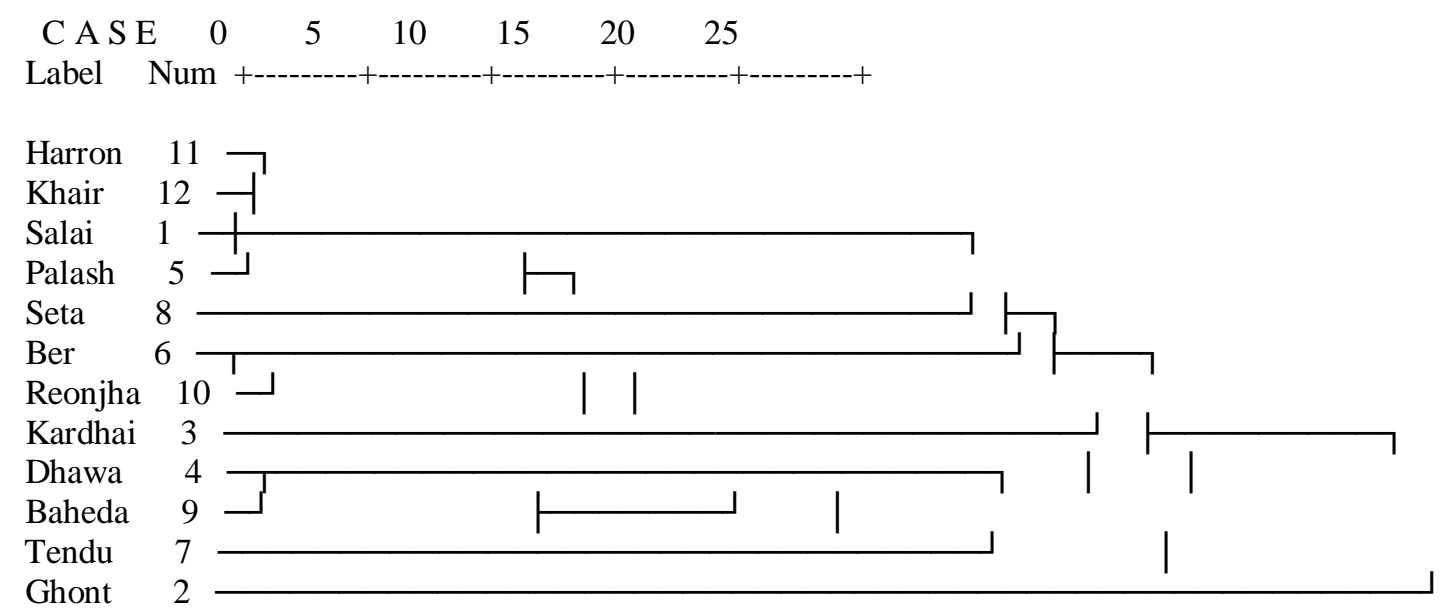

Fig. 3. Cluster Analysis of Presence/Absence of Herbivorous species with Habitat type

As the analysis suggests, clustered vegetation types have similar terrain and floral community structure as they support similar herbivore species. Harron, Khair, Salai and Palash vegetation types support all the six species. Ber and Reonja support herbivores except wild pig. The Dhawa and Baheda vegetation types, both are utilized by a total of five species except Langur.

\subsection{Habitat Suitability Modeling}

The general assumption of predicting habitat of a species is that if a species is spotted several times in a certain location with certain biophysical attributes, then it will be highly probable that it occurs in areas that fulfill exactly the same attributes. Based on this assumption, it was predicted that Chital which were encounter frequently is suitable to habitat of open mixed forest type with high density grassland at a gentle to moderate slope and nearness to water availability. The darker red color to dark orange color contours (Fig. 4) indicates highest to high chances of habitat area prefer by chital whereas light to lightest yellow color contour indicates seldom to any chance of habitat preferences. Chinkara and Nilgai were another herbivorous species encountered that share $80 \%$ of Chital habitats preferences while these two species were also predicted to like mixed forest type. The high value of contour lines shows the area of high habitat preference while, moderate to very low values indicate little to no preference of the habitat type (Fig. $5 \& 6$ ). Similarly, Sambar is predicted to be most suitable in the habitat where there is dark brown color or high value contours (Fig. 7) while lighter color contours indicates low preference of the habitat. The dark brown color contours are the habitats area of high canopy density of trees at a moderate to high altitude slope. The light color contours are the habitats of open mixed forests and other forest type.

It is hereby justify that though the models show the habitat preferences of the prey species according to their encounter rate, it cannot be totally assumpts that the resulted model is the best habitat as ecological systems are dynamic. Therefore, the removal and addition of some of the biophysical attributes that may not be directly related to the species can seriously affect the distribution of these species. 


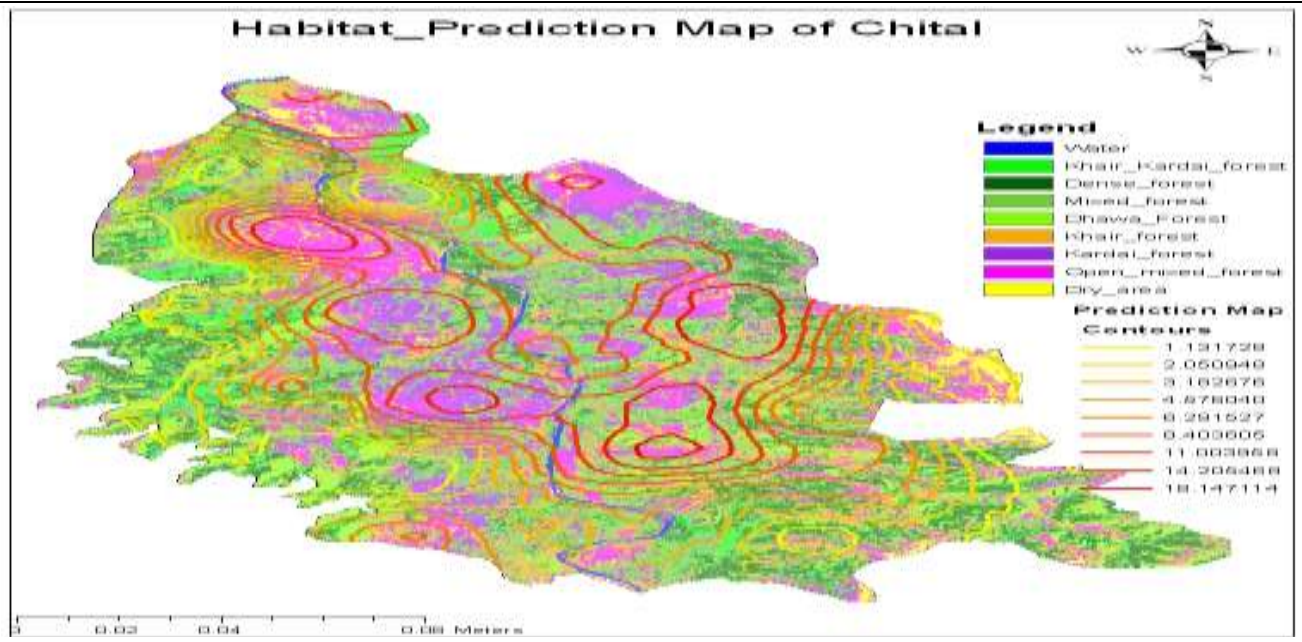

Fig. 4. Prediction/ Model of Habitat range of Chital - Areas covering Dark to darker contours shows high probability of Chital habitat preference over other habitats which may be due to the presence of easy food, and nearest to water sources.

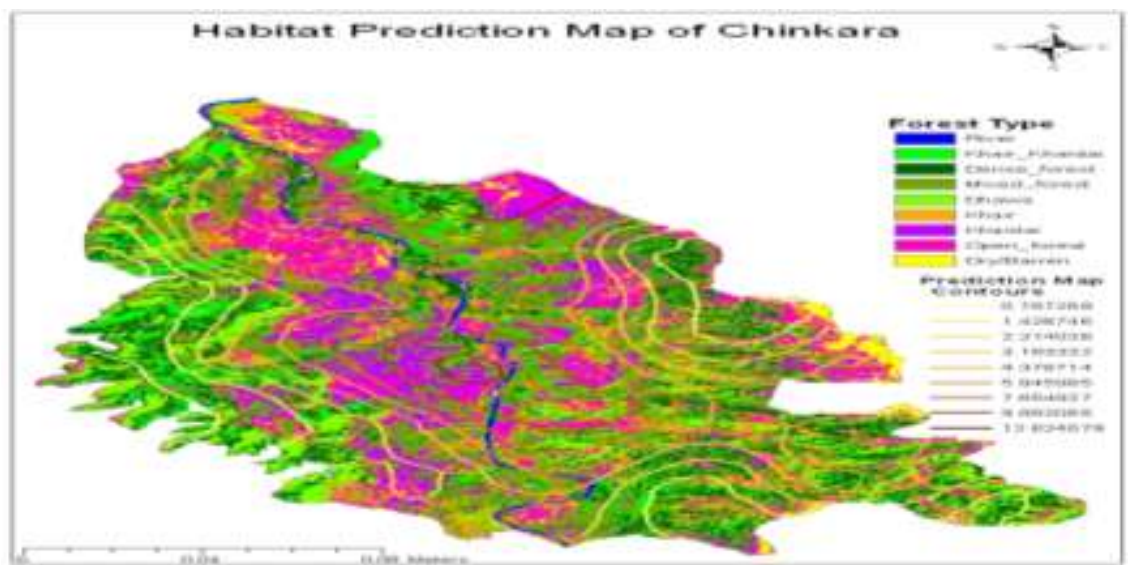

Fig. 5. Prediction/ Model of Habitat range of Chinkara- Chinkara will be most probably found near the open mixed forest and mixed forest regions and also nearby the water bodies

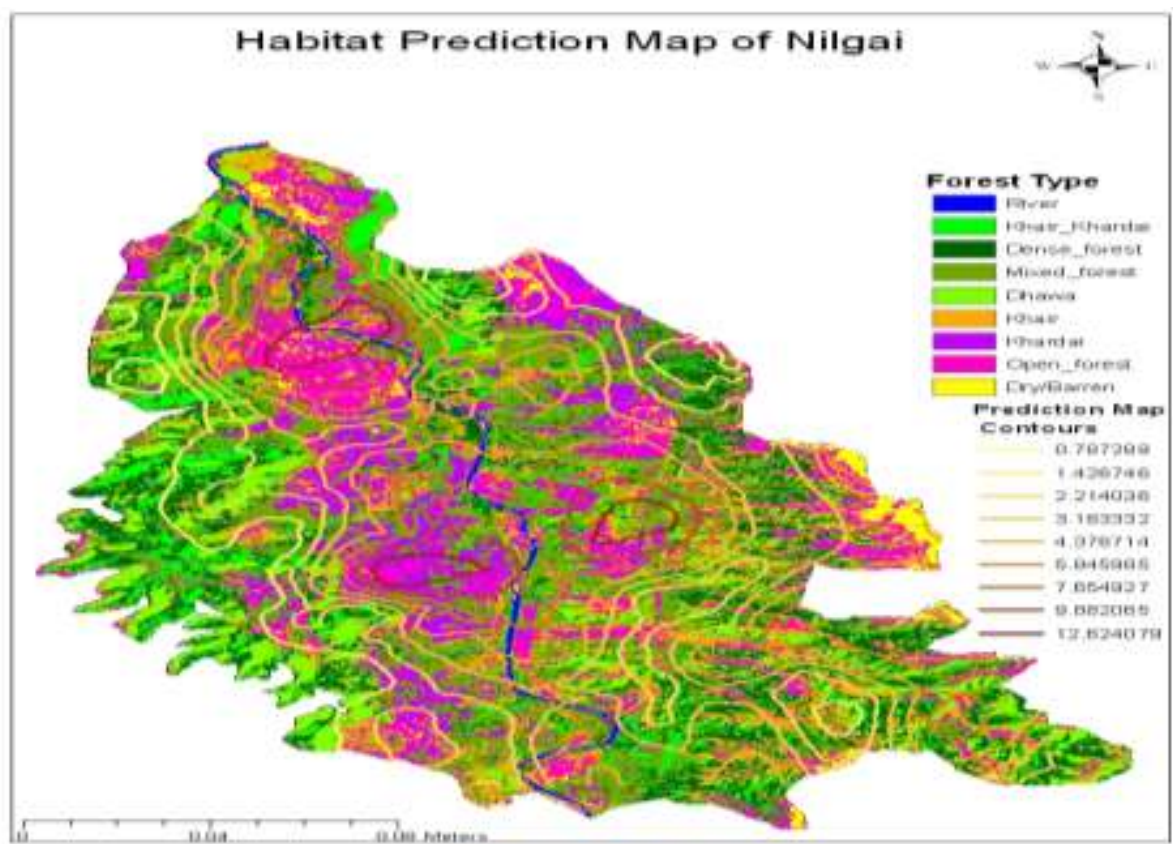

Fig. 6. Prediction/ Model of Habitat range of Nilgai- Nilgai is also predicted to be found in open mixed forest in the sanctuary 


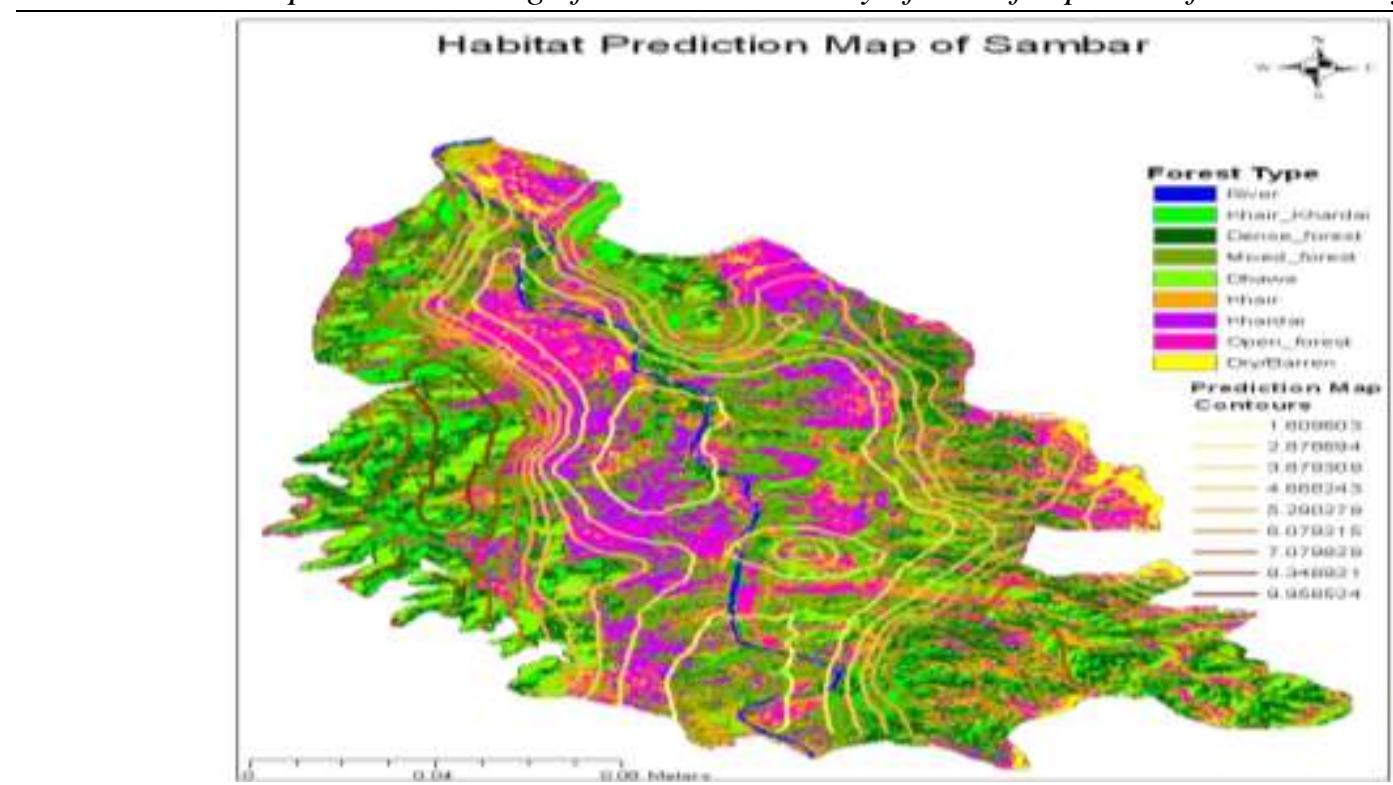

Fig. 7. Prediction/ Model of Habitat range of Sambar-Sambar is most likely to be found in dense and mixed forest and at moderate steep regions.

\section{DISCUSSION}

In this study, supervised classification was used to categorize the habitat type of Kuno Wildlife Sanctuary which was based on the analysis in the reflectance of spectral radiance (signature) of different forest crown cover classes with integration of good ground truthing and the available topography maps and other literature. The method of habitat mapping by means of signature classification was applied throughout the 1990s (eg. [23], [24], [25], [12]) and still used today ( [26], [27]). Similarly, ([28]) analyzed vegetation types for wildlife habitat evaluation using Remote Sensing. Accordingly, the habitat type of Kuno Wildlife Sanctuary was categorize into 9 classes such as Mixed forest, Dense Forest, Open Forest, Kardhai forest, Khair- Kardhai forest, Dhawa forest, Khair forest, Dry/ Barren land and Water bodies. Mixed forest type was the dominant class with an area of $23.4 \%$ of the forest type followed by Dense forest (16.9\%), Kardhai forest (12.9\%), Dhawa forest (12.8\%), Khair forest (11.8\%), Open mixed forest (11.1\%), Khair-Kardhai forest (7.4\%), Dry barren area (2.9\%) and open water bodies $(0.8 \%)$. Similarly in 2005, Faiyaz A. Khudsar in his study of the sanctuary found that mixed forest was the dominant class with an area of $25 \%$ of the forest type followed by Dense forest (23\%), Kardhai forest (17\%), Open mixed forest (15\%), Mixed Kardhai forest (10\%), Khair forest (6\%), Dhawa forest $(2 \%)$ and Khair-Kardhai forest $(2 \%)$. The minor difference in the area covered by different habitat might be due to climatic factor controlling the seasons of the year.

The most straightforward approach to estimate animal distribution or preferable habitat from remotely sensed data is to identify and detect the exact areas where the species is occupying ([29]). Patterns of species distribution on the ground have been shown to be associated with the distribution of environmental variables such as topography, rainfall, soil type and disturbances ([30]). A GIS model based on elevation, slope, aspect and proximity to a water source, etc., in conjunction with ground-based species database and broad vegetation types derived from Remote Sensing help in identifying the spatial pattern of the species assemblages in accordance with the habitats. Also the general assumption of predicting habitat of a species is that if a species is spotted several times in a certain location with certain biophysical attributes, then it will be highly probable that it occurs in areas that fulfill exactly the same attributes. Therefore keeping in mind the above factors, the habitat suitability maps of some of the frequently encountered wildlife species such as Chital, Chinkara, Nilgai and Sambar were predicted.

Chital being a generalist feeder was seen distributed almost uniformly throughout the sanctuary and occupied the widest niche ([17]). It was predicted that Chital is suitable to habitat of open mixed forest type with high density grassland at a gentle to moderate slope of $5^{\circ}-13^{\circ}$ and nearness to water availability. However, a good number of cattles approximately around 2042, which have been left by the villages when they move out of the sanctuary, have become feral ([31]) in the meantime also shared major habitat as Chital. This population of feral animals forms part of the prey base for any large carnivores inside the park. Chinkara and Nilgai were another herbivorous species encountered that share $80 \%$ of Chital habitats preferences while these two species were also predicted to like mixed forest type. Except Sambar which was encountered at higher slope, all the wild herbivores utilized almost the same habitat as Chital as observed from the spatial distribution seen in the map. Similarly, Sambar is predicted to be most suitable in the habitat of high canopy density of trees at a moderate to high altitude slope. Altitude information is effectively useful along with a Remote Sensing derived 
vegetation map to spatially delineate different species assemblages ([32], [33]). [34] and [35] also successfully used multispectral remote-sensing data and elevation- slope complexes to delineate different species assemblages in evergreen forest of Tirunelvi-hills of Western Ghats, Tamil Nadu.

Species-specific characteristics related to the appearance and behavior of the species, as well as the habitats used by the species, can influence the species detection probability ([36]). Habitat models created for the same species in different locations may consist of entirely different sets of habitat variables ([37]). One of the most important factors to the success of habitat suitability modeling is the species distribution data that is correlated to the environmental predictors. Most multivariate statistical techniques used for habitat suitability modeling, such as logistic regression and discriminant function analysis, require both presence and absence data. However, absence data are frequently not available or are difficult to obtain reliably ([38]). Particularly for elusive and difficult to detect species, failing to detect a species during a survey does not result in a reliable absence classification ([36]). Species with a low probability of detection may have a large number of false absences in survey data. False absences in presence/absence data occur when the species is actually present at a site, but the species is not detected in the survey. The distribution of species locations along habitat variables may differ from the entire study area in terms of the mean (marginality) and/or variance (specialization). A species with high marginality prefers habitat that is different from the overall mean of the study area. A species with high specialization occurs at a very restricted range of a habitat variable in relation to the distribution of the variable for the entire study area. Habitat variables that are key to the marginality and specialization of the species can be determined and it is possible to compute habitat suitability across a gridded study area to produce a habitat suitability map provided that the same study area is used, comparisons among species can be made in terms of their marginality, specialization, and predicted habitat suitability. Many factors including sampling methods, environmental conditions, species-specific characteristics, and population density of the species can influence the detectability of a species during a survey.

\section{ACKNOWLEDGEMENT}

The authors would like to thank Madhya Pradesh Forest Department Gwalior for permission and encouragement.

\section{References}

[1] K.P. Mccarthy, R.J. Fletcher, C.T. Rota, and R.L. Hutto, Predicting Species Distributions from Samples Collected along Roadsides, Conservation Biology, 26 (1), 2011, 68-77.

[2] B.A. Loiselle, C.A. Howell, C.H. Graham, J.M. Goerck, T. Brooks, K.G. Smith and P.H. Williams, Avoiding pitfalls of using species distribution models in conservation planning, Conservation Biology, 17, 2003, 1591-1600.

[3] T.D. Penman, D.L. Binns and R.P. Kavanagh, Patch-occupancy modeling as a method for monitoring changes in forest floristic: a case study in southeastern Australia. Conservation Biology, 23, 2009, 740-749.

[4] J.J. Lawler, S.L. Shafer and A.R. Blaustein, Projected climate impacts for the amphibians of the Western Hemisphere, Conservation Biology, 24, 2010, 38-50.

[5] D.A. Stow, A.S. Hope and T.H. George, Reflectance characteristics of arctic tundra vegetation from airborne radiometry, International Journal of Remote Sensing, 14(6), 1989, 1239-1244.

[6] D.A. Stow, A.S. Hope, D. Richardson, D. Chen, C. Garrison and D. Service, Potential of colour-infrared digital camera imagery for inventory and mapping of alien plant invasions in South African shrub lands, International Journal of Remote Sensing, 21(15), 2000, 2965-2970.

[7] M.A. Haltuch, P.A. Berkman and D.W. Garton, Geographic information system (GIS) analysis of ecosystem invasion: Exotic mussels in Lake Erie, Limnology and Oceanography, 45, 2000, 1778-1787.

[8] C.M. McCormick, Mapping exotic vegetation in the Everglades from large-scale aerial photographs, Photogrammetric Engineering and Remote Sensing, 65(2), 1999, 179-184.

[9] L.C. Rowlinson, M. Summerton and F. Ahmed, Comparison of Remote Sensing data sources and techniques for identifying and classifying alien invasive vegetation in riparian zones, Water South Africa, 25(4), 1999, 497-500.

[10] H. Nagendra, C. Tucker and L. Carlson, Monitoring parks through Remote Sensing studies in Nepal and Honduras. Environmental Management, 34, 2004, 748-760.

[11] G.P. Asner, D. E. Knapp and E.N. Broadbent, Selective logging in the Brazilian Amazon, Science, 310, $2005,480-482$.

[12] M. Cardillo, D.W. Macdonald and S.P. Rushton, Predicting mammal species richness and distributions: testing the effectiveness of satellite-derived land cover data. Landscape Ecology, 14 (5), 1999, 423-435.

[13] I.M.A. Heitkonig, S. Ringrose, G.F. Epema, C. Bonyongo, E. Veenendaal, A. Stein, A. Breeuwer, M. Hasselt, E. Klop, J. Goethem and M. Slot, Watching wildlife from space, in T. Bernard, K. Mosepele, L. Ramberg (Eds.), International Wetlands Conference, Botswana, 2003.

[14] W.G. Rees, M. Wiiliams and P. Vitebsky, Mapping land cove change in a reindeer herding area of the Russian Arctic using Landsat TM and ETM+ imagery and indigenous knowledge, Remote Sensing of Environment, 85(4), 2003, 441-452.

[15] C. Mongkolswat and P. Thirangoon, Application of Satellite Imagery and GIS to Wildlife Habitat Suitability Mapping, AARSACRS, 1998, Available from: http://www.gisdevelopment.net.

[16] H. Nagendra, Incorporating landscape transformation into local conservation prioritization: a case study in the Western Ghats, India. Biodiversity and Conservation, 2001, 353-365.

[17] F.A. Khudsar, Monitoring Wildlife Population and Biodiversity Assessment in the Proposed Lion Re-introduction Site, the Kuno Wildlife Sanctuary, Madhya Pradesh, India, doctoral diss., Jiwaji University, Gwalior, 2008.

[18] L.K. Chaudhary, Management Plan of Kuno-Palpur Sanctuary-Annual Drafts Part I and Part II (Madhya Pradesh Forest Department, Gwalior, 2001).

[19] P. Rho, Using a landscape ecological approach to develop a wildlife habitat model in Korea, Seoul, Korea Environment Institute, 2004. 
[20] F.A. Khudsar, K. Sharma, R.J. Rao and R.S. Chundawat, Estimation of prey base and its implication in Kuno Wildlife Sanctuary, Journal of Bombay Natural History Society, 105(1), 2008, 42-48.

[21] W.T. Thompson, Toward reliable bird surveys: accounting for individuals present but not detected, Auk, 119, 2002, 18-25.

[22] S.S. Rosenstock, D.R. Anderson, K.M. Giesen, T. Leukering and M.F. Carter, Landbird counting techniques: Current practices and an alternative, $A u k, 119,2002,46-53$

[23] T.P. Huber, and K.E. Casler, Initial analysis of Landsat TM data for elk habitat mapping, International Journal of Remote Sensing, 11(5), 1990, 907-912.

[24] H.F. Del Valle, D.A. De Lamo and D.A. Gagliardini, Environmental affinity of the guanaco (Lama guanicoe Muller, Camelidae) in two selected areas of Central Patagonia supported by ERS-1 SAR data, Earth Obs. Q. 55, 1997, 14-19.

[25] R.M. Fuller, G.B. Groom, S. Mugisha, A. Katende, P. Ipulet, D. Pomeroy, R. Bailey and R. Ogutu-Ohwayo, The integration of field survey and Remote Sensing for Biodiversity Assessment: A case study in the tropical forests and wetlands of Sango Bay, Uganda, Biological Conservation, 86(3), 1998, 379-391.

[26] B.O. Oindo, A.K. Skidmore and P. De Salvo, Mapping habitat and biological diversity in the Maasai Mara ecosystem, International Journal of Remote Sensing, 24 (5), 2003, 1053-1069.

[27] B.D. Sharma. J. Clevers, R. De Graaf, and N.R. Chapagain, Mapping Equus kiang (Tibetan wild Ass) Habitat in Surkhang, Upper Mustang, Nepal, Mountain Research and Development, 24 (2), 2004, 149-156.

[28] P.S. Roy and S.A. Ravan, Biomass estimation using satellite remote sensing data - An investigation on possible approaches for natural forest, Journal of Biosciences, 21(4), 1996, 535-561.

[29] E. Leyequien, J. Verrelst, M. Slot, G. Schaepman-Strub, I. M.A. Heitko"nig and A. Skidmore, Capturing the fugitive: Applying remote sensing to terrestrial animal distribution and diversity, International Journal of Applied Earth Observation and Geoinformation, 9, 2007, 1-20.

[30] M.S.R. Murthy, A. Giriraj and C.B.S. Dutt, Geoinformatics for biodiversity assessment, Biollett, 40(2), 2003, 75-100, Available from: http://www.biollett.amu.edu.pl.

[31] K. Banerjee, Estimating the ungulate abundance and developing the habitat specific effective strip width models in Kuno Wildlife Sanctuary, Madhya Pradesh, M.Sc. dissertation, Forest Research Institute, Dehradun, 2005.

[32] P.S. Roy, M.C. Porwal and L. Sharma, Mapping of Hippophaerhamnoides Linn. in the adjoining areas of Kaza in Lahul and Spiti using Remote Sensing and GIS, Current Science, 80, 2001, 1107-1111.

[33] M.C. Porwal, L. Sharma and P.S. Roy, Stratification and mapping of Ephedra gerardiana Wall. in Poh (Lahul and Spiti) using Remote Sensing and GIS, Current Science, 84, 2003, 208-212.

[34] Giriraj, M.S.R. Murthy, S. Britto and C.B.S. Dutt, Phyto-diversity in intact and fragmented evergreen habitats, Tamil Nadu, India: A conjunctive analysis using RS and ground data, Proc. 30th International Symposium on Remote Sensing and Environment, Hawaii, 2003.

[35] Giriraj, M.S.R. Murthy, C.B.S. Dutt and B.R. Ramesh, Phytodiversity and endemic habitat analysis in wet evergreen forest of Tirunelveli hills (Tamil Nadu) using remote sensing and GIS, National Remote Sensing Agency Report, Hyderabad, India, 2003b.

[36] P.B. Bayley and J.T. Peterson, An approach to estimate probability of presence and richness of fish species. Transactions of the American Fisheries Society, 130, 2001, 620-633.

[37] S. Manel, J.M. Dias, and S.J. Ormerod, Comparing discriminant analysis, neural networks and logistic regression for predicting species distributions: a case study with a Himalayan river bird, Ecological Modeling, 120, 1999, 337-347.

[38] A.H. Hirzel, J. Hausser, D. Chessel and N. Perrin, Ecological- niche factor analysis: how to compute habitat suitability maps without absence data? Ecology, 83, 2002, 2027-2036. 